\title{
Circadian modulation of calcium levels in cells in the suprachiasmatic nucleus
}

\author{
Christopher S. Colwell \\ Mental Retardation Research Center, Department of Psychiatry and Biobehavioural Sciences, \\ University of California-Los Angeles, 760 Westwood Plaza, Los Angeles, CA 90024-1759, USA
}

\section{Abstract}

There is reason to believe that resting free calcium concentration $\left[\mathrm{Ca}^{2+}\right]_{\mathrm{i}}$ in neurons in the suprachiasmatic nucleus ( $\mathrm{SCN}$ )may vary with the circadian cycle. In order to start to examine this hypothesis, optical techniques were utilized to estimate resting $\mathrm{Ca}^{2+}$ levels in SCN cells in a rat brain slice preparation. $\left[\mathrm{Ca}^{2+}\right]_{\mathrm{i}}$ measured from the soma was significantly higher in the day than in the night. Animals from a reversed light-dark cycle were used to confirm that the phase of the rhythm was determined by the prior light-dark cycle. The rhythm in $\mathrm{Ca}^{2+}$ levels continued to be expressed in tissue collected from animals maintained in constant darkness, thus confirming the endogenous nature of this variation. Interestingly, the rhythm in $\mathrm{Ca}^{2+}$ levels was not observed when animals were housed in constant light. Finally, the rhythm in $\mathrm{Ca}^{2+}$ levels was prevented when slices were exposed to tetrodotoxin (TTX), a blocker of voltage-sensitive sodium channels. Similar results were obtained with the voltage-sensitive $\mathrm{Ca}^{2+}$ channel blocker methoxyverapamil. These observations suggest a critical role for membrane events in driving the observed rhythm in $\mathrm{Ca}^{2+}$. Conceptually, this rhythm can be thought of as an output of the circadian oscillator. Because $\left[\mathrm{Ca}^{2+}\right]_{\mathrm{i}}$ is known to play a critical role in many cellular processes, the presence of this rhythm is likely to have many implications for the cell biology of SCN neurons.

\section{Keywords}

calcium oscillations; circadian rhythms; fura2; Rattus rattus; SCN

\section{Introduction}

The circadian timing system regulates many aspects of an organism's behaviour and physiology. In mammals, the part of the nervous system responsible for most circadian behaviour can be localized to a pair of structures in the hypothalamus known as the suprachiasmatic nucleus ( $\mathrm{SCN}$ ). Importantly, when these cells are removed from the organism and maintained in a brain slice preparation, they continue to generate $24-\mathrm{h}$ rhythms. Previous studies suggest that the basic mechanism responsible for the generation of these rhythms is intrinsic to individual cells in the SCN (Welsh et al., 1995) and perhaps in other cell populations (Balsalobre et al., 1998). The core molecular mechanism driving these

(C) European Neuroscience Association

Correspondence: Professor C. S. Colwell, as above. ccolwell@mednet.ucla.edu. 
cellular oscillations appears to be a negative feedback loop operating at the level of transcription/translation (e.g. Reppert, 1998; Sangoram et al., 1998; Wilsbacher \& Takahashi, 1998). Nevertheless, the paths by which environmental signals travel to the oscillatory mechanism and by which the oscillatory mechanism regulates other physiological processes clearly travels through the cell membrane. A critical unanswered question then is how changes at the level of the membrane alter transcription and, conversely, how rhythmic gene expression alters membrane events.

Although these signalling mechanisms in SCNneurons are just beginning to be defined, there are several suggestions that $\mathrm{Ca}^{2+}$ may be involved. First, $\mathrm{Ca}^{2+}$ is known to regulate many of the diverse processes, e.g. membrane potential, secretion and gene expression that show circadian oscillations. The widespread nature of $\mathrm{Ca}^{2+}$ regulatory actions led previous workers to speculate that this ion would be an ideal component of the circadian oscillatory system (Goto et al., 1985; Hasegawa et al., 1998). Second, a light-regulated $\mathrm{Ca}^{2+}$ influx which appears to play a role in the molecular mechanisms by light alters the phase of the circadian system in several preparations including mammalian SCN(Ding et al., 1998; Obrietan et al., 1998), molluscan BRNs (McMahon \& Block, 1987; Colwell et al., 1994), and perhaps the pineal (Zatz \& Heath, 1995). Finally, in tobacco and Arabidopsis plants expressing a transgene for $\mathrm{Ca}^{2+}$-sensitive luminescent protein apoaequorin, it has been possible to demonstrate circadian oscillations in $\left[\mathrm{Ca}^{2+}\right]_{\mathrm{i}}$ (Johnson et al., 1995). Thus, it became of interest to determine if a circadian oscillation in $\left[\mathrm{Ca}^{2+}\right]_{\mathrm{i}}$ may also be found in mammalian pacemaker neurons in the SCN.

In order to address this issue, the present study utilized optical imaging techniques and fura2-AM to measure $\mathrm{Ca}^{2+}$ levels in $\mathrm{SCN}$ cells in a brain slice preparation. As a first step, a day-night comparison was made between basal $\mathrm{Ca}^{2+}$ levels in SCNslices from animals maintained in a light-dark (LD) cycle. Animals from a reversed LD cycle were used to confirm that the phase of the rhythm was determined by the prior LD cycle. Next, experiments were run to determine whether any diurnal variation would remain when animals were placed in constant darkness or constant light. The expression of circadian rhythms will continue in constant darkness yet, in many cases, will dampen out in constant light. Finally, the sodium channel blocker tetrodotoxin (TTX) and the $\mathrm{Ca}^{2+}$ channel blocker methox verapamil were used to examine the contribution of these voltage-sensitive currents.

\section{Materials and methods}

\section{Animals and brain slice preparation}

The UCLA Animal Research Committee approved the experimental protocols used in this study. Brain slices were prepared using standard techniques from rats (Sprague-Dawley) between 10 and 14 days old. For reasons that are not completely understood, infrared (IR) differential interference contrast (DIC) video microscopy and bulk dye loading with acetoxymethyl (AM) esters work better in slices from young animals. The circadian oscillator based in the SCN is functional by this age (e.g. Reppert \& Schwartz, 1984). Rats were killed by decapitation, brains dissected and placed in cold oxygenated artificial cerebral spinal fluid (ACSF) containing (in $\mathrm{mM}$ ): $\mathrm{NaCl}, 130 ; \mathrm{NaHCO}_{3}, 26 ; \mathrm{KCl}, 3 ; \mathrm{MgCl}_{2}$, 5; $\mathrm{NaH}_{2} \mathrm{PO}_{4}, 1.25 ; \mathrm{CaCl}_{2}, 1.0$; glucose, 10 (pH 7.2-7.4). After cutting slices, transverse 
sections $(350 \mu \mathrm{m})$ were placed in $\operatorname{ACSF}\left(25-27^{\circ} \mathrm{C}\right)$ for at least $1 \mathrm{~h}$ (in this solution $\mathrm{CaCl}_{2}$ was increased to $2 \mathrm{mM}, \mathrm{MgCl}_{2}$ was decreased to $2 \mathrm{mM}$ and $4 \mathrm{mM}$ lactate was added). Slices were constantly oxygenated with $95 \% \mathrm{O}_{2}-5 \% \mathrm{CO}_{2}$. Slices were placed in a perfusion chamber (Warner Instruments, CT, USA) attached to the stage of the fixed-stage upright microscope. The slice was held down with thin nylon threads glued to a platinum wire and submerged in continuously flowing, oxygenated $\operatorname{ACSF}\left(25^{\circ} \mathrm{C}\right)$ at $2 \mathrm{~mL} / \mathrm{min}$. Solution exchanges within the slice were achieved by a rapid gravity feed delivery system. In our system, the effects of bath-applied drugs begin within $15 \mathrm{~s}$ and are typically complete by $1-$ 2 min.

\section{IR DIC video microscopy}

Slices were viewed with an upright compound microscope (BX50 Olympus, NY, USA), using a water immersion lens ( $40 \mathrm{X})$ and DIC optics. They were illuminated with near IR light by placing an IR bandpass filter $(750-1050 \mathrm{~nm})$ in the light path. The image was detected with an IR-sensitive video camera (C2400 Hamamatsu, NJ, USA) and displayed on a video monitor. A camera controller allowed analogue contrast enhancement and gain control. Cells were typically visualized from 30 to $100 \mu \mathrm{m}$ below the surface of the slice. In the present study, IR video microscopy was utilized to visualize cells within the brain slice and to limit some of the uncertainty as to the cell type. This imaging technique allowed us to clearly see the SCNand to exclude cells from the surrounding hypothalamic regions. In addition, morphological criteria were used to target SCNneurons and to avoid taking measurements from cells that were clearly glia. While size is hardly foolproof, in a few cases, electrophysiological recording and fluorescent imaging were combined to demonstrate that the cells from which $\mathrm{Ca}^{2+}$ levels were being measured indeed show the electrical properties of neurons $(n=4)$. Accordingly, it is likely that most of the data were collected from SCN neurons.

\section{Calcium imaging}

A cooled CCD camera (Microview model 1317 X 1035 pixel format, Princeton Instruments, NJ, USA) was added to the Olympus fixed-stage microscope to measure fluorescence. In order to load the dye into cells, slices were incubated in membrane-permeable fura 2 AM (50 $\mu \mathrm{M})$ at $35^{\circ} \mathrm{C}$ for $10 \mathrm{~min}$. Empirically, we have found that this protocol results in wellloaded neurons in the SCNbrain slice preparation. The fluorescence of fura 2 was excited alternatively at wavelengths of $357 \mathrm{~nm}$ and $380 \mathrm{~nm}$ by means of a high-speed wavelengthswitching device (Lambda DG-4; Sutter, CA, USA). Image analysis software (MetaFlour, Universal Imaging, PA, USA) allowed the selection of several 'regions of interest' within the field from which measurements are taken. In order to minimize bleaching, the intensity of excitation light and sampling frequency was kept as low as possible. In these experiments the intensity of excitation light was measured as $18 \mu \mathrm{W}$ out of the objective, and measurements were normally made once every $2 \mathrm{~s}$.

\section{Calibration of $\mathrm{Ca}^{2+}$ signals}

Free $\left[\mathrm{Ca}^{2+}\right]$ was calculated from the ratio $(\mathrm{R})$ of fluorescence at 357 and $380 \mathrm{~nm}$, using the following equation: $\left[\mathrm{Ca}^{2+}\right]=K_{\mathrm{d}} \mathrm{X} S f \mathrm{X}\left(R-R_{\min }\right) /\left(R_{\max }-R\right)$ (Grynkiewicz et al., 1985). 
The value of $K_{\mathrm{d}}$ was assumed to be $135 \mathrm{nM}$, while values for $R_{\min }$ and $\mathrm{R}_{\max }$ were all determined via calibration methods. Initially, an in vitro method was used to estimate values. With this method, rectangle glass capillaries were filled with a high-Ca ${ }^{2+}$ (fura $2+10$ $\mathrm{mM} \mathrm{Ca}^{2+}$ ), a low-Ca ${ }^{2+}$ (fura2 $+10 \mathrm{mM}$ EGTA) and a control saline without fura2. The fluorescence $(F)$ at $380 \mathrm{~nm}$ excitation of the low- $\mathrm{Ca}^{2+}$ solution was imaged and the exposure of the camera adjusted to maximize the signal. These camera settings were then fixed and measurements made with 380 and $357 \mathrm{~nm}$ excitation of the three solutions. $R_{\min }=F 357 \mathrm{~nm}$ in low- $-\mathrm{Ca}^{2+} / F 380$ in low-Ca ${ }^{2+} ; R_{\max }=\mathrm{F} 357$ in high- $\mathrm{Ca}^{2+} / \mathrm{F} 380$ in high-Ca ${ }^{2+} ; \mathrm{Sf}=\mathrm{F} 380$ in low-Ca ${ }^{2+} / F 380$ in high-Ca ${ }^{2+}$. In addition, an in vivo calibration method was also used. For this, SCN cells were loaded via the patch pipette using solutions inside the electrode similar to the normal internal solution but containing either no $\mathrm{Ca}^{2+}(20 \mathrm{mM}$ EGTA) or $10 \mathrm{mM}$ $\mathrm{Ca}^{2+}$ for $R_{\min }$ and $R_{\max }$, respectively.

\section{Lighting conditions}

In order to look for possible diurnal variation in $\mathrm{Ca}^{2+}$ levels, animals were maintained on a daily LD cycle consisting of $12 \mathrm{~h}$ of light followed by $12 \mathrm{~h}$ of dark. It is already well established that cells in the SCNcontinue to show circadian oscillations when isolated from the animal in a brain slice preparation. Accordingly, care must be taken as to the time in the daily cycle when the data are collected. All of the animals were killed 30 min before the time that the lights would have turned off in the LD cycle. The data from these animals were collected between zeitgeber time (ZT) 13-18 and pooled to form a 'night' group. For comparison, some of the animals were killed immediately after the lights came on. The data from these animals were collected between ZT 1-6 and pooled to form a 'day' group.

\section{Statistical analyses}

Between-group differences were evaluated using $t$-tests or Mann-Whitney rank sum tests when appropriate. Values were considered significantly different if $P<0.05$. All tests were performed using SigmaStat (SPSS, IL, USA). In the text, values are shown as mean \pm SEM.

\section{Results}

Data were collected from a total of 1320 cells from 65 animals. All groups contained data from at least five animals. Each of these cells was determined to be within the SCNby directly visualizing the cell's location with IR DIC video microscopy before any $\mathrm{Ca}^{2+}$ data were collected (Fig. 1). A bulk loading procedure was used to load cells with a membranepermeable form of the $\mathrm{Ca}^{2+}$ indicator dye fura2. This procedure produced an even loading of many cells in SCNslices from young animals (Fig. 2; 10-14-day-old rats were used in the current study). Cells that exhibited uneven loading due to dye sequestration were not included in the data set. Small cell types including glia were easily identified and were not included in the data set. In four cases, a single cell was filled with the $\mathrm{Ca}^{2+}$ indicator dye by loading through a patch pipette. In each case, the cell could generate action potentials and thus had the electrical properties of a neuron. $\mathrm{Ca}^{2+}$ levels in each cell were sampled every 2 $\mathrm{s}$ for a total of $5 \mathrm{~min}$. The average value over this 5 -min interval was viewed to be the cell's resting $\mathrm{Ca}^{2+}$ level. No cell was sampled more than once. The stability of these measurements was determined by examining how measured values changed through time in 
fura2-loaded SCN cells in the absence of stimulation. Sampling every $2 \mathrm{~s}$ for a total of 10 min, the raw intensity values changed by $4 \pm 1 \%$ after 5 min and by $8 \pm 2 \%$ after $10 \mathrm{~min}$ $(n=54)$.

\section{Diurnal rhythm in resting $\mathrm{Ca}^{2+}$ levels in $\mathrm{SCN}$ cells}

The first experiment was designed to determine whether resting, non-stimulated $\mathrm{Ca}^{2+}$ levels in SCNneurons varied between day and night. These experiments were performed with brain slices taken from animals during their day and compared with data obtained from brain slices from animals during their night (Fig. 3). Rats were killed immediately after lights-on for the 'day' group or immediately before lights-off for the 'night' group. Other than the time that the animals were killed, all other conditions between the day and night groups remained constant. Each cell was measured only once. The data were collected between ZT $0-6$ and ZT 12-18, and were pooled to form a 'day' and 'night' group. There was a daily rhythm in $\left[\mathrm{Ca}^{2+}\right]_{\mathrm{i}}$ with measured values significantly higher (118\%) during the day than during the night $(P<0.001)$. $\left[\mathrm{Ca}^{2+}\right]_{\mathrm{i}}$ was estimated to be $135 \pm 6 \mathrm{nM}(n=238)$ for the day group and $62 \pm 3 \mathrm{nM}(n=180)$ for the night group. This rhythm was not observed in SCNcells taken from animals that were less than 7 days old. In these animals, the night levels were not significantly different from the day (day, $141 \pm 5 \mathrm{nM}, n=91$; night, $135 \pm 5$ $\mathrm{nM}, n=55$ ). In order to demonstrate that the phase of the rhythm was determined by the prior LD cycle, a group of animals $(n=10)$ was housed in a 'reversed' LD cycle (Fig. 3 ). Again, $\mathrm{Ca}^{2+}$ values were significantly higher $(55 \%)$ during the day $(152 \pm 4 \mathrm{nM}, n=174)$ then during the night ( $98 \pm 2 \mathrm{nM}, n=212$ ), suggesting that the observed daily variation is determined by the phase of the LD cycle and not some other unknown variable.

A major source of autofluorescence appears to be due to the NADH molecule, and there is some concern that a daily rhythm in autofluorescence could be produced as a by-product of the well-established daily rhythm in cellular metabolism in the SCN. In the brain slice, the autofluorescent signal measured from the SCNcells averaged $16 \pm 0.6$ arbitrary intensity units, while the signal from the dye-loaded cells averaged $314 \pm 2.5$. While this confirms the presence of a measurable autofluorescent signal from the brain slice (e.g. Brooke et al., 1996), this signal did not vary significantly from day and night, and would have a minor impact on the measured rhythm.

\section{Rhythm in $\mathrm{Ca}^{2+}$ appears to be circadian}

In order to demonstrate that any diurnal rhythm is circadian, it is necessary to show that the rhythm continues in constant darkness. For these experiments, animals were placed in constant darkness for 2 days prior to the preparation of brain slices. The data were collected between circadian time (CT) 0-6 and CT 12-18 and were pooled to form a 'subjective day' and 'subjective night' group (Fig. 4). Again, there was a daily rhythm in $\mathrm{Ca}^{2+}$ with measured values significantly higher (57\%) during the subjective day then during the subjective night $(P<0.001)$. Free $\mathrm{Ca}^{2+}$ concentration was estimated to be $144 \pm 3 \mathrm{nM}(n=191)$ for the day group and $91 \pm 3 \mathrm{nM}(n=142)$ for the night group. In many organisms, including rats, exposure to bright constant light prevents the expression of circadian rhythms in locomotor activity and body temperature (e.g. Depres-Brummer et al., 1995; Cambras et al., 1998). One explanation for this phenomenon is that the constant light stops the motion of the 
central oscillatory mechanisms (e.g. Pittendrigh, 1966). Accordingly, it was of interest to determine the effect of constant light on the rhythm in $\mathrm{Ca}^{2+}$. For this experiment, animals were placed in constant light for 10-14 days prior to the preparation of brain slices (Fig. 4). Under these conditions, there was no measurable rhythm in $\mathrm{Ca}^{2+}$ levels (day, $143 \pm 5 \mathrm{nM}, n$ $=76$; night, $132 \pm 5 \mathrm{nM}, n=51$ ). The observations that the rhythm continues in constant darkness, but not in constant light, strongly suggest that the rhythm is circadian in nature.

\section{Rhythm in $\mathrm{Ca}^{2+}$ blocked by ion channel blockers}

Finally, in order to gain some insights into the mechanisms underlying these rhythms, the ion channel blockers TTX and methoxyverapamil were applied (Fig. 5).

Electrophysiological tech-niques were used to confirm that application of TTX $(1 \mu \mathrm{M})$ blocked voltage-gated $\mathrm{Na}^{+}$currents, and methoxyverapamil $(500 \mu \mathrm{M})$ significantly inhibited high-voltage-activating $\mathrm{Ca}^{2+}$ currents in SCN neurons. In the presence of TTX, the rhythm in $\mathrm{Ca}^{2+}$ was not observed (day, $81 \pm 2 \mathrm{nM}, n=131$; night, $78 \pm 4 \mathrm{nM}, n=69$ ). Because $\mathrm{Ca}^{2+}$ influx through voltage-activated channels is a major source of action potential-induced $\mathrm{Ca}^{2+}$ increases (e.g. Lev-Ram et al., 1992; Miyakawa et al., 1992; Muri \& Knopfel, 1994; Bollmann et al., 1998), some experiments were run in the presence of the $\mathrm{Ca}^{2+}$ channel blocker methoxyverapamil. After application of methoxyverapamil, the rhythm in $\mathrm{Ca}^{2+}$ was not observed (day, $76 \pm 4 \mathrm{nM}, n=33$; night, $68 \pm 3 \mathrm{nM}, n=45$ ). In both cases, it was the higher day levels that were significantly inhibited by application of these ion channels blockers while the night levels were not significantly impacted. The net result was the loss of the rhythm in the presence of these inhibitors.

\section{Discussion}

In the present study, imaging techniques and the indicator dye fura2 were utilized to estimate basal $\mathrm{Ca}^{2+}$ levels in SCNcells of the mammalian hypothalamus. The resulting data indicate that there was a daily rhythm of $\mathrm{Ca}^{2+}$. The phase of this rhythm was determined by the $\mathrm{LD}$ cycle to which the rats were exposed with the $\mathrm{Ca}^{2+}$ levels peaking during the day. This rhythm exhibited some of the properties of a circadian oscillation with the rhythm continuing when animals were held in constant darkness but not constant light. Finally, the rhythm was blocked by the application of a voltage-sensitive $\mathrm{Na}^{+}$or $\mathrm{Ca}^{2+}$ ion channel blocker. Overall, the results suggest the presence of a circadian oscillation of resting $\left[\mathrm{Ca}^{2+}\right]_{\mathrm{i}}$ in SCNcells that is driven by the rhythm in electrical activity.

The measured rhythm was a relatively low amplitude oscillation. The peak levels during the day were estimated to average $135 \mathrm{nM}$ while levels during the night fell to $62 \mathrm{nM}$. The $\mathrm{Ca}^{2+}$ influx associated with action potential firing is thought to produce a brief, highconcentration (> $100 \mu \mathrm{M}$ ), localized gradient of $\mathrm{Ca}^{2+}$ near open $\mathrm{Ca}^{2+}$ channels (e.g. Zucker, 1996; Rahamimoff \& Fernandez, 1997; Neher, 1998). These gradients are rapidly dissipated by diffusion and binding to buffers, and would not be seen by slow, volume-averaged measurements used in the present study. However, these rapid influxes would contribute to the $\mathrm{Ca}^{2+}$ load in a slower and diffuse $\mathrm{Ca}^{2+}$ pool that is referred to as residual $\mathrm{Ca}^{2+}$ (e.g. Delaney \& Tank, 1994; Tank et al., 1995). It is this pool that the current study measured with the high-affinity $\mathrm{Ca}^{2+}$ indicator fura2. 
The $\left[\mathrm{Ca}^{2+}\right]_{\mathrm{i}}$ in the cytoplasm results from the highly regulated balance between the rates of $\mathrm{Ca}^{2+}$ influx and removal. Although the current study did not explore the possibility of circadian regulation of $\mathrm{Ca}^{2+}$ removal mechanisms, there is good reason to suspect that the rhythm in basal $\left[\mathrm{Ca}^{2+}\right]_{\mathrm{i}}$ can be accounted for by a daily rhythm in $\mathrm{Ca}^{2+}$ influx. SCNneurons are known to exhibit a daily rhythm of spontaneous neural activity with activity peaking during the day at $\sim 5-10 \mathrm{~Hz}$ (Inouye \& Kawamura, 1979; Green \& Gillette, 1982; Groos \& Hendriks, 1982; Shibata et al., 1982). This rhythm may be driven by a daily rhythm in membrane conductance (Jiang et al., 1997; Schaap et al., 1999). Therefore, the simplest explanation for the observed rhythm in $\mathrm{Ca}^{2+}$ is that it is driven by membrane events. The observation that the rhythm is not seen in the presence of the ion channel blockers TTX or methoxyverapamil certainly supports this interpretation. In addition, the magnitude of the daily change $(\sim 70 \mathrm{nM})$ is consistent with the results of other studies investigating the effects of acute electrical activity on $\mathrm{Ca}^{2+}$ levels in the soma (Regehr \& Tank, 1990, 1992; Knopfel \& Gahwiler, 1992; Miyakawa et al., 1992; Muri \& Knopfel, 1994; Wong et al., 1998). One of the unique aspects of the data from the current study is the suggestion that SCNneurons undergo steady-state changes in $\left[\mathrm{Ca}^{2+}\right]_{\mathrm{i}}$ that last for hours.

Conceptually it is useful to think of the circadian system as having three components: (i) an oscillator or clock responsible for the generation of the daily rhythm; (ii) input pathways by which the environment and other components of the nervous system provide information to the oscillator; and (iii) output pathways by which the oscillator provides temporal information to a wide range of physiological and behavioural control centres. The results of previous studies suggest that a glutamate-induced $\mathrm{Ca}^{2+}$ influx is part of the input pathway by which light causes phase shifts of the circadian system (Colwell \& Menaker, 1996; Ding et al., 1998; Obrietan et al., 1998). The data in the present study are most consistent with $\mathrm{Ca}^{2+}$ also acting as an output of the circadian system. Perhaps, most convincing, is the observation that the ion channel blockers TTX and methoxyverapamil block expression of the rhythm. Previous studies have shown that TTX blocks input to and outputs from the circadian system but does not stop the underlying clock mechanisms (e.g. Schwartz et al., 1987; Earnest et al., 1991; Shibata \& Moore, 1993). In addition, the rhythm in $\mathrm{Ca}^{2+}$ could not be measured from animals of less than 7 days old. The SCNoscillations measured by glucose metabolism develop prior to birth (e.g. Reppert \& Schwartz, 1984). Thus, developmental disassociation also argues against this rhythm in $\mathrm{Ca}^{2+}$ being essential for the generation of the circadian oscillation. Finally, our current understanding is that the core biochemical clock mechanisms involve rhythmic expression of transcription factors, e.g. mPer, that feedback to alter their own transcription on a circadian time scale. It is possible, even likely, that some components of this core molecular mechanisms are $\mathrm{Ca}^{2+}$ sensitive. For example, recent evidence suggests that basic-loop-helix proteins are a critical positive element driving this molecular feedback loop (Gekakis et al., 1998; Hogenesch et al., 1998; Sangoram et al., 1998). There is evidence that activity of basic-loop-helix proteins can be repressed by an increase in intracellular $\mathrm{Ca}^{2+}$ concentration (Hermann et al., 1998).

Although the $\mathrm{Ca}^{2+}$ dependence $\left(K_{\mathrm{d}}\right)$ of this regulation is not known, this is one mechanism by which the rhythm in $\mathrm{Ca}^{2+}$ may influence the core molecular mechanisms that underlie circadian oscillations. Nevertheless, for the reasons discussed above, it does not appear to be likely that rhythmic $\mathrm{Ca}^{2+}$ levels are needed to drive this oscillation. In this context, it is best 
to think about the rhythm in $\mathrm{Ca}^{2+}$ levels as an output of the circadian oscillator. A similar conclusion was reached by Johnson and colleagues working in plant systems (Johnson et al., 1995). Utilizing tobacco and Arabidopsis plants expressing a transgene for $\mathrm{Ca}^{2+}$-sensitive luminescent protein apoaequorin, these workers were also able to demonstrate circadian oscillations in $\left[\mathrm{Ca}^{2+}\right]_{\mathrm{i}}$. These observations raise the possibility that circadian oscillations in cytosolic $\mathrm{Ca}^{2+}$ may be a widespread feature of circadian timing systems.

\section{Acknowledgements}

This work was supported by Whitehall Foundation grant \#F98P15, a Frontiers in Science Award from the Howard Hughes Institute, and NIH \#HL64582. I am also grateful to Dr A. Konnerth (University of Saarland, Germany) whose laboratory generously aided in the collection of the preliminary data upon which this study was based.

\section{Abbreviations}

ACSF artificial cerebrospinal fluid

AM acetoxymethyl

CT circadian time

DIC differential interference contrast

IR infrared

LD light-dark

SCN suprachiasmatic nucleus

TTX tetrodotoxin

ZT zeitgeber time

\section{References}

Balsalobre A, Damiola F, Schibler U. A serum shock induces circadian gene expression in mammalian tissue culture cells. Cell. 1998; 93:929-937. [PubMed: 9635423]

Bollmann JH, Helmchem F, Borst JGG, Sakmann B. Postsynaptic $\mathrm{Ca}^{2+}$ influx mediated by three different pathways during synaptic transmission at a calyx-type synapse. J. Neurosci. 1998; 18:10409-10419. [PubMed: 9852578]

Brooke SM, Trafton JA, Sapolsky RM. Autofluorescence as a confound in the determination of calcium levels in hippocampal slices using fura-2AM dye. Brain Res. 1996; 706:283-288. [PubMed: 8822368]

Cambras T, Vilaplana J, Torres A, Canal MM, Casamitjana N, Campuzano A, Diez-Noguera A. Constant bright light (LL) during lactation in rats prevents arrhythmicity due to LL. Physiol. Behav. 1998; 63:875-882. [PubMed: 9618011]

Colwell, CS.; Menaker, M. Regulation of circadian rhythms by excitatory amino acids. In: Brann, DW.; Mahesh, VB., editors. Excitatory Amino Acids: Their Role in Neuroendocrine Function. CRC Press; New York: 1996. p. 223-252.

Colwell CS, Whitmore D, Michel S, Block GD. Calcium plays a central role in phase shifting the ocular circadian pacemaker of Aplysia. J. Comp. Physiol. 1994; 175:415-423. [PubMed: 7965916]

Delaney KR, Tank DW. A quantitative measurement of the dependence of short-term synaptic enhancement on presynaptic residual calcium. J. Neurosci. 1994; 14:5885-5902. [PubMed: 7931551] 
Depres-Brummer P, Levi F, Metzger G, Touitou Y. Light-induced suppression of the rat circadian system. Am. J. Physiol. 1995; 268:R111-R1116.

Ding JM, Buchanan GF, Tischkau SA, Kuriashkina L, Faiman LE, Alster JM, McPherson PS, Campbell KP, Gillette MU. A neuronal ryanodine receptor mediates light-induced phase delays of the circadian clock. Nature. 1998; 394:381-384. [PubMed: 9690474]

Earnest DJ, DiGiorgio SM, Sladek CD. Effects of tetrodotoxin on the circadian pacemaker mechanism in suprachiasmatic explants in vitro. Brain Res. Bull. 1991; 26:677-682. [PubMed: 1933388]

Gekakis N, Staknis D, Nguyen HB, Davis FC, Wilsbacher LD, King DP, Takahashi JS, Weitz CJ. Role of the CLOCK protein in the mammalian circadian mechanism. Science. 1998; 280(5369):15641569. [PubMed: 9616112]

Goto K, Laval-Martin DL, Edmunds LN. Biochemical modeling of an autonomously oscillatory circadian clock in Euglena. Science. 1985; 228:1284-1288. [PubMed: 2988128]

Green DJ, Gillette R. Circadian rhythm of firing rate recorded from single cells in the rat suprachiasmatic brain slice. Brain Res. 1982; 245:198-200. [PubMed: 6889453]

Groos GA, Hendriks J. Circadian rhythm in electrical discharge of rat suprachiasmatic nucleus recorded in vitro. Neurosci. Lett. 1982; 34:283-288. [PubMed: 6298675]

Grynkiewicz G, Poenie M, Tsien RY. A new generation of $\mathrm{Ca}^{2+}$ indicators with greatly improved fluorescence properties. J. Biol. Chem. 1985; 260:3440-3450. [PubMed: 3838314]

Hasegawa K, Kikuchi H, Ishizaki S, Tamura A, Tsukahara Y, Nakaoka Y, Iwai E, Sato T. Simple fluctuation of $\mathrm{Ca}^{2+}$ elicits the complex circadian dynamics of cyclic AMP and cyclic GMP in Paramecium. J. Cell Sci. 1998; 112:201-207. [PubMed: 9858473]

Hermann S, Saarikettu J, Onions J, Hughes K, Grundstrom T. Calcium regulation of basic helix-loophelix transcription factors. Cell Calcium. 1998; 23:135-142. [PubMed: 9601609]

Hogenesch JB, Gu YZ, Jain S, Bradfield CA. The basic-helixloop helix PAS orphan MOP3 forms transcriptionally active complexes with circadian and hypoxia factors. Proc. Natl Acad. Sci. USA. 1998; 95:5474-5479. [PubMed: 9576906]

Inouye ST, Kawamura H. Persistence of circadian rhythmicity in a mammalian hypothalamic 'island' containing the suprachiasmatic nucleus. Proc. Natl Acad. Sci. USA. 1979; 76:5962-5966. [PubMed: 293695]

Jiang ZG, Yang YQ, Liu ZP, Allen CN. Membrane properties and synaptic inputs of suprachiasmatic nucleus neurons in rat brain slices. J. Physiol. (Lond.). 1997; 499:141-159. [PubMed: 9061646]

Johnson CH, Knight MR, Kondo T, Masson P, Sedbrook J, Haley A, Trewavas A. Circadian oscillations of cytosolic and chloroplastic free calcium in plants. Science. 1995; 269:1863-1865. [PubMed: 7569925]

Knopfel T, Gahwiler BH. Activity-induced elevations of intracellular calcium concentration in pyramidal and nonpyramidal cells of the CA3 region of rat hippocampal slice cultures. J. Neurophysiol. 1992; 68:961-963. [PubMed: 1432060]

Lev-Ram V, Miyakawa H, Lasser-Ross N, Ross WN. Calcium transients in cerebellar purkinje neurons evoked by intracellular stimulation. J. Neurophysiol. 1992; 68:1167-1177. [PubMed: 1432076]

McMahon DG, Block GD. The Bulla ocular circadian pacemaker. J. Comp. Physiol. 1987; 161:335346. [PubMed: 3668876]

Miyakawa H, Ross WN, Jaffe D, Callaway JC, Lasser-Ross N, Lisman JE, Johnston D. Synaptically activated increases in $\mathrm{Ca} 2+$ concentration in hippocampal CA1 pyramidal cells are primarily due to voltage-gated Ca2+ channels. Neuron. 1992; 9:1163-1173. [PubMed: 1361128]

Muri R, Knopfel T. Activity induced elevations of intracellular calcium concentration in neurons of the deep cerebellar nuclei. J. Neurophysiol. 1994; 71:420-428. [PubMed: 8158239]

Neher D. Vesicle pools and $\mathrm{Ca}^{2+}$ microdomains: new tools for understanding their roles in neurotransmitter release. Neuron. 1998; 20:389-399. [PubMed: 9539117]

Obrietan K, Impey S, Storm DR. Light and circadian rhythmicity regulate MAP kinase activation in the suprachiasmatic nuclei. Nature Neurosci. 1998; 1:693-700. [PubMed: 10196585]

Pittendrigh CS. The circadian oscillation in Drosophila pseudoobscurea pupae: a model for the photoperiod clock. Z. Pflanzenphysiol. 1966; 54:275-307. 
Rahamimoff R, Fernandez JM. Pre- and postsynaptic regulation of transmitter release. Neuron. 1997; 18:17-27. [PubMed: 9010202]

Regehr WG, Tank DW. Postsynaptic NMDA receptor-mediated calcium accumulation in hippocampal CA1 pyramidal cell dendrites. Nature. 1990; 345:807-810. [PubMed: 1972782]

Regehr WG, Tank DW. Calcium dynamics in synaptically activated pyramidal cells. J. Neurosci. 1992; 12:4202-4223. [PubMed: 1359030]

Reppert SM. A clockwork explosion! Neuron. 1998; 21:1-4. [PubMed: 9697845]

Reppert SM, Schwartz WJ. The suprachiasmatic nuclei of the fetal rat: characterization of a functional circadian clock using 2-deoxyglucose. J. Neurosci. 1984; 4:1677-1682. [PubMed: 6737036]

Sangoram AM, Saez L, Antoch MP, Gekakis N, Staknis D, Whiteley A, Fruechte EM, Vitaterna MH, Shimomura K, King DP, Young MW, Weitz CJ, Takahashi JS. Mammalian circadian autoregulatory loop: a timeless ortholog and mPer1 interact and negatively regulate CLOCKBMAL1-induced transcription. Neuron. 1998; 21:1101-1113. [PubMed: 9856465]

Schaap J, Bos NPA, de Jeu MTG, Geurtsen AMS, Meijer JH, Pennartz CMA. Neurons of the rat suprachiasmatic nucleus show a circadian rhythm in membrane properties that is lost during prolonged whole-cell recording. Brain Res. 1999; 815:154-166. [PubMed: 9974136]

Schwartz WJ, Gross RA, Morton MT. The suprachiasmatic nuclei contain a tetrodotoxin-resistant circadian pacemaker. Proc. Natl Acad. Sci. USA. 84. 1987:1694-1698. [PubMed: 3470750]

Shibata S, Moore RY. Tetrodoxoin does not affect circadian rhythms in neuronal activity and metabolism in rodent suprachiasmatic nucleus in vitro. Brain Res. 1993; 606:259-266. [PubMed: 8490718]

Shibata S, Oomura Y, Kita H, Hattori K. Circadian rhythmic changes of neuronal activity in the suprachiasmatic nucleus of the rat hypothalamic slice. Brain Res. 1982; 247:154-158. [PubMed: 7127113]

Tank DW, Regehr WG, Delaney KR. A quantitative analysis of presynaptic calcium dynamics that contribute to short-term enhancement. J. Neurosci. 1995; 15:7940-7952. [PubMed: 8613732]

Wilsbacher LD, Takahashi JS. Circadian rhythms: molecular basis of the clock. Curr. Opin. Genet. Dev. 1998; 8:595-602. [PubMed: 9794822]

Wong WT, Sanes JR, Wong ROL. Developmentally regulated spontaneous activity in the embryonic chick retina. J. Neurosci. 1998; 18:8839-8852. [PubMed: 9786990]

Welsh DK, Logothetis DE, Weister M, Reppert SM. Individual neurons dissociated from rat suprachiasmatic nucleus express independently phase circadian firing patterns. Neuron. 1995; 14:697-706. [PubMed: 7718233]

Zatz M, Heath JR. Calcium and photoentrainment in chick pineal cells revisited: effects of caffeine, thapsigargin, EGTA, and light on the melatonin rhythm. J. Neurochem. 1995; 65:1332-1341. [PubMed: 7643111]

Zucker RS. Exocytosis: a molecular and physiological perspective. Neuron. 1996; 17:1049-1055. [PubMed: 8982154] 

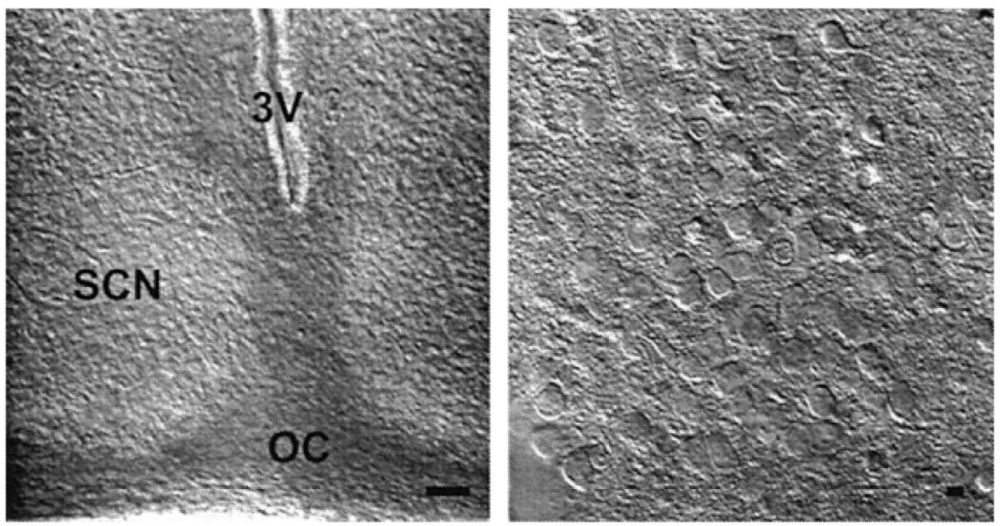

FIG. 1.

Neurons in SCN brain slices visualized by IR DIC video microscopy. Left: image of SCNunder lower power magnification. Scale bar, $100 \mu \mathrm{M}$. 3V, third ventricle; OC, optic chiasm. Right: higher power view of same slice. Scale bar, $10 \mu \mathrm{m}$. This technology allows a clear view of soma and, in some cases, processes of SCNcells. In the present study, this technology was used primarily to identify cells in the SCNregion for further analysis and to exclude cells from the surrounding hypothalamic regions. Tissue from 14-day-old rat. 


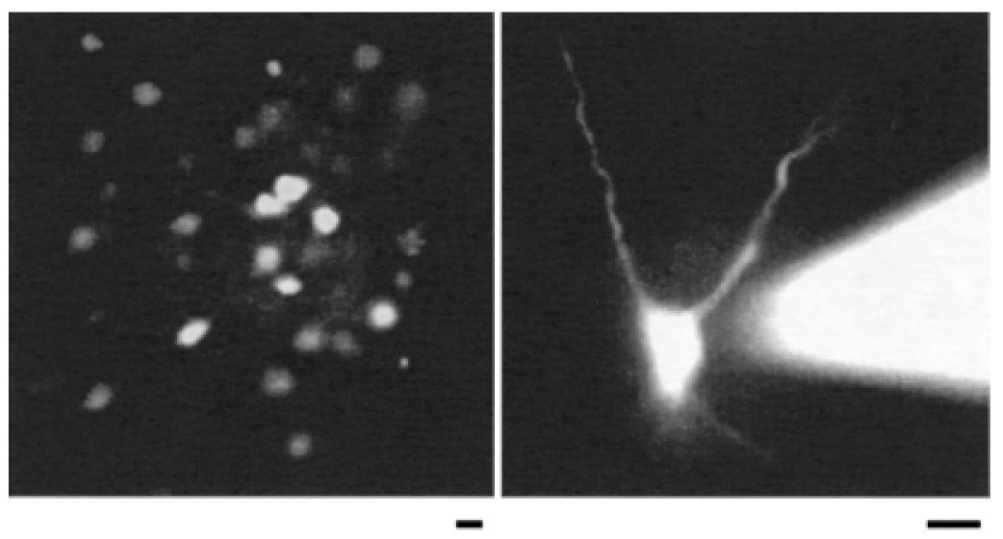

FIG. 2.

SCNcells in brain slice loaded with the $\mathrm{Ca}^{2+}$ indicator dye fura2. Left: SCNcells in brain slice preparation bulk loaded with the fura2 AM. Right: SCNcell loaded with fura2 salt through the patch pipette. Cells were excited at $380 \mathrm{~nm}$ and images were over-exposed to aid in visualization of the filled cells. Rats were 14 days old. 

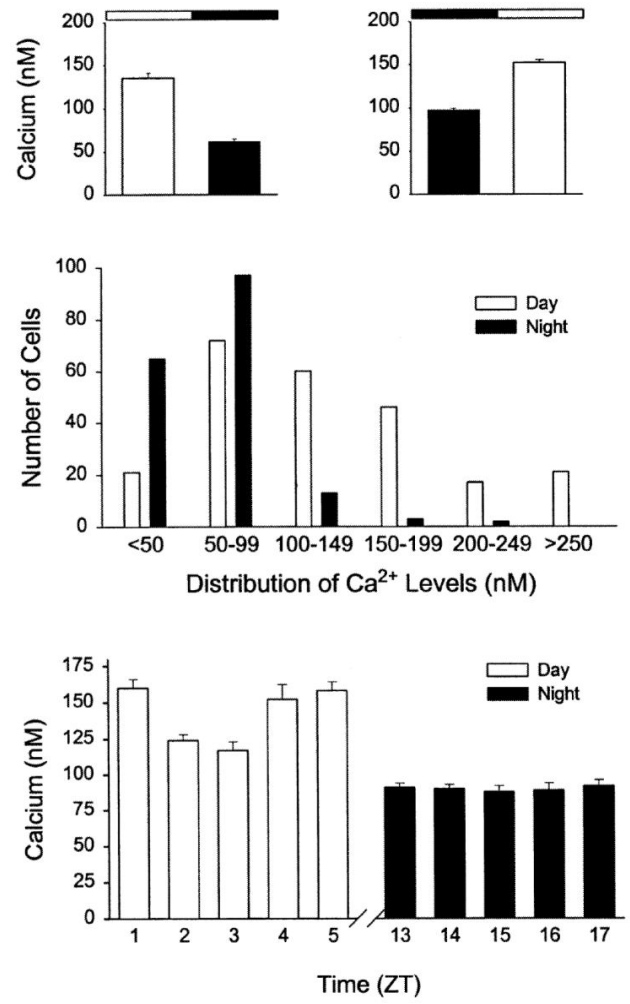

FIG. 3.

Diurnal rhythm of resting $\mathrm{Ca}^{2+}$ levels in cells in the $\mathrm{SCN}$. In these experiments, resting $\mathrm{Ca}^{2+}$ levels were estimated in SCNneurons in brain slices from animals during their day and compared with data obtained from brain slices from animals during their night. Animals were killed at either ZT 0 for the day group or ZT 12 for the night group. Each cell is sampled only once. Top panels: histograms showing that $\mathrm{Ca}^{2+}$ levels in SCNcells peak during the day. $\left[\mathrm{Ca}^{2+}\right]_{\mathrm{i}}$ was estimated to be $135 \pm 6 \mathrm{nM}(n=238)$ for the day group and $62 \pm$ $3 \mathrm{nM}(n=180)$ for the night group $(P<0.001)$. When the phase of the light-dark cycle to which the animals were exposed was reversed, so did the resulting rhythm. This result demonstrates that the observed daily variation is determined by the phase of the LD cycle and not some other unknown variable. Middle panel: histograms illustrating the daily variation in the distribution of $\mathrm{Ca}^{2+}$ levels. Bottom panel: histograms illustrating average $\mathrm{Ca}^{2+}$ levels as a function of time from which the data were collected. 


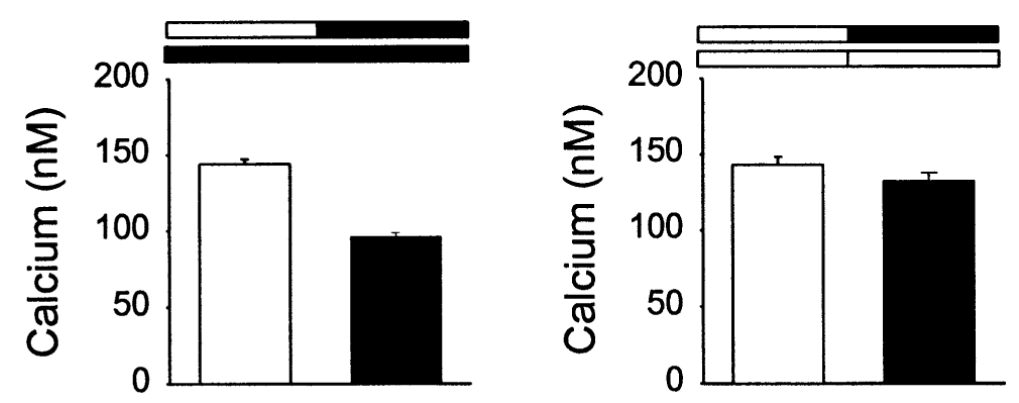

FIG. 4.

Circadian rhythm of resting $\mathrm{Ca}^{2+}$ levels in cells in the SCN. In these experiments animals were maintained in constant conditions and resting $\mathrm{Ca}^{2+}$ levels were estimated in SCNneurons in brain slices from animals during their subjective day and compared with data obtained from brain slices from animals during their subjective night. Left panel: when animals were maintained in constant dark, the rhythm in $\mathrm{Ca}^{2+}$ levels in SCNcells continues to be observed with phase determined by prior LD cycle. Right panel: when animals were placed in bright constant light for 10-14 days, the rhythm in $\mathrm{Ca}^{2+}$ levels was no longer observed. The observations that the rhythm continues in constant darkness, but not in constant light, strongly suggest that the rhythm in $\left[\mathrm{Ca}^{2+}\right]_{\mathrm{i}}$ is circadian. 

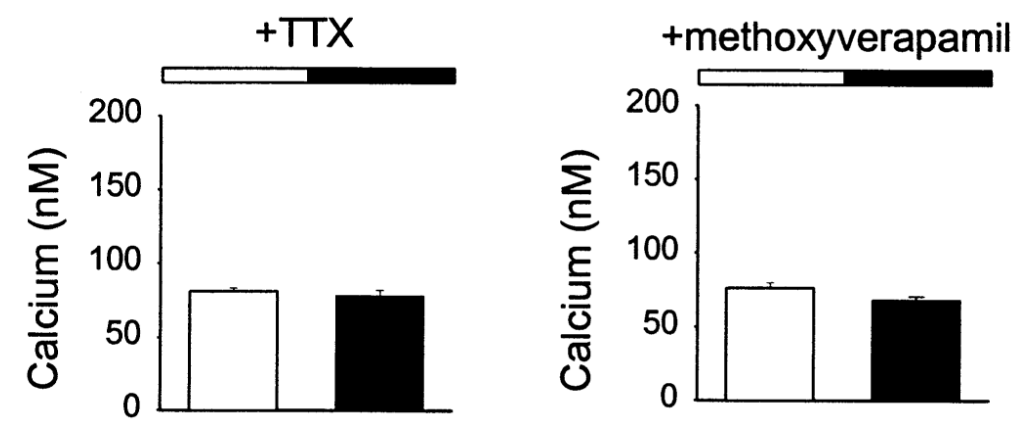

FIG. 5.

Daily rhythm in $\mathrm{Ca}^{2+}$ levels was blocked by application of ion channel inhibitors. In these experiments, resting $\mathrm{Ca}^{2+}$ levels were estimated in SCN neurons in brain slices from animals during their day and compared with data obtained from brain slices from animals during their night. Left panel: in the presence of TTX, the rhythm in $\mathrm{Ca}^{2+}$ was not observed (day, $81 \pm 2 \mathrm{nM}, n=131$; night, $78 \pm 4 \mathrm{nM}, n=69$ ). Right panel: in the presence of methoxyverapamil, the rhythm in $\mathrm{Ca}^{2+}$ was not observed (day, $76 \pm 4 \mathrm{nM}, n=33$; night, 68 $\pm 3 \mathrm{nM}, n=45)$. In both cases, it was the higher day levels that were significantly inhibited $(P<0.001)$ by application of these inhibitors, while the night levels were not significantly impacted. The net result was the loss of the rhythm in the presence of these ion channel inhibitors. 